\title{
Açóes avaliativas oficiais: para que avaliar?
}

Maria Alice de Sousa Carvalho*

\section{Resumo}

Pretende-se, neste texto, discutir as ações avaliativas propostas pelo Ministério de Educação (MEC), especialmente com relação aos programas Índice de Desenvolvimento da Educação Básica (Ideb) e Prova Brasil, no Decreto n. 6094 (BRASIL, 2007). Essas açōes serão estudadas considerando-se o contexto das políticas educacionais desenvolvidas desde os anos de 1990, em que houve uma reformulação do papel do Estado, a fim de assegurar um conjunto de açóes educacionais organizadas em três eixos: avaliação, gestáo e financiamento. Ao fazer essa análise, espera-se contribuir para a discussão referente à função da avaliação nos programas nacionais oficiais.

Palavras-chave: política educacional, educação básica, avaliação, índice de educação básica.

Official assessment: why assess?

Abstract

The aim of this study is to discuss the assessment proposed by the Ministry of Education in Decree 6094 (BRASIL, 2007), in particular, the programs Basic Education Index and the Brazil Test. Assessment is studied, taking into consideration the context of the educational policies drawn up since the 1990s, in which the role of the State was reformulated, in order to guarantee the provision of a set of educational actions based on three axes: assessment, management and financing. This analysis would hope to contribute to the discussion on the role of assessment in official national programs.

Keywords: educational policy, basic education, assessment, basic education index.

\section{Avaliar as ações educativas por meio de mecanismos externos é um processo recente no Brasil. Trata-se, porém, de uma tendência que se vem consolidando nos vários sistemas de ensino federal, estadual e municipal.}

* Professora de Português do Centro de Ensino e Pesquisa Aplicada à Educação (Cepae), da Universidade Federal de Goiás (UFG). Doutora em Educação.E-mail: masc.3@hotmail.com. 
Nesse sentido, o país dispóe de leis e programas nacionais desenvolvidos com a finalidade de materializar esse processo. Entretanto, é necessário problematizar a função da avaliação na atualidade, nos documentos e programas do governo federal. Qual a concepção de avaliação tomada como referência para subsidiar as propostas? Com qual objetivo é realizada a avaliação? Seus resultados traduzem-se em açóes que visam melhorar as instituiçóes educacionais? Ou pretendem dar visibilidade a dados escalonados, estimulando uma competição desleal entre as escolas e/ou justificando o fracasso da escola pública para reduzir ainda mais seus poucos recursos? Com base nessas questóes, pretende-se analisar os procedimentos avaliativos definidos a partir do Decreto n. 6094 (BRASIL, 2007/2012).

O Decreto n. 6094 (BRASIL, 2007/2012) dispóe sobre o Plano de Metas Compromisso de Todos pela Educação, assinado pelo então presidente do Brasil, Luis Inácio da Silva, em 24 de abril de 2007. Conforme este documento, seu objetivo é melhorar a qualidade da educação básica mediante programas de assistência técnica e financeira em regime de colaboração com a sociedade. Ele abrange diferentes açóes em diversos níveis e modalidades do ensino que versam sobre financiamento, avaliação, gestão, formação de professores, dentre outras. A respeito da avaliação, institui o Índice do Desenvolvimento da Educação Básica (Ideb), cujo objetivo é

medir a qualidade de cada escola e de cada rede de ensino. O indicador é calculado com base no desempenho do estudante em avaliaçóes do Inep e em taxas de aprovação. Assim, para que o Ideb de uma escola ou rede cresça é preciso que o aluno aprenda, não repita o ano e frequente a sala de aula. [...] O índice é medido a cada dois anos e o objetivo é que o país, a partir do alcance das metas municipais e estaduais, tenha nota 6 em 2022 - correspondente à qualidade do ensino em países desenvolvidos. (BRASIL, p. 1, 2008a)

Conforme Saviani (2007), a maioria das ações previstas neste documento e organizadas dentro do Plano de Desenvolvimento da Educaçáo (PDE) não mantém uma conexão interna e não está relacionada às metas do Plano Nacional de Educação (PNE), aprovado pelo Congresso Nacional em 9 de janeiro de 2001. Para Saviani (2007, p. 1239), "ele não parte do diagnóstico, das diretrizes e dos objetivos e metas constitutivos do PNE, mas se compóe de açóes que não se articulam organicamente com este". Além disso, sua principal interlocução foi com o empresariado, ao assumir a agenda do Compromisso de Todos pela Educação. 
Esse plano de metas Compromisso de Todos pela Educação foi patrocinado por entidades privadas, como o Grupo Pão de Açúcar, Fundação Itaú, Fundação Roberto Marinho, Grupo Gerdau, Instituto Airton Senna, dentre outras que, interessadas nas questóes educacionais, resolveram se aliar ao governo e definir algumas metas a serem atingidas, tais como:

1.Todas as crianças e jovens de 4 a 17 deverão estar na escola; 2 . Toda criança de 8 anos deverá ler e escrever; 3 . Todo aluno deverá aprender o que é apropriado para a série; 4 . Todos os alunos deverão concluir o ensino fundamental e o médio. 5. O investimento necessário na educaçâo básica deverá estar garantido e bem gerido. (SAVIANI, 2007, p. 1244)

De acordo com Neves (2005, p. 95), no artigo "A sociedade civil como espaço estratégico de difusão da nova pedagogia da hegemonia", o "Estado, não sem tensões e contradições, vem intensificando, com todos os instrumentos legais e ideológicos a seu dispor, o seu papel de educador, ou seja, de instrumento de conformação cognitiva e comportamental do brasileiro ao projeto de sociabilidade burguesa implementado pelos governos anteriores".

Segundo essa autora, na tentativa de obter o consenso da sociedade para a re-educação ético-política, individual e coletiva na direçáo do atendimento das demandas econômico-coorporativistas das classes dominantes, o Estado vem incentivando, como estratégia, a criação de novos sujeitos coletivos. Estes são centrados nos interesses extraeconômicos e na execução das políticas sociais governamentais, como parece ser o caso da iniciativa dos empresários reunidos em torno da agenda do Compromisso de Todos pela Educação.

Além de tentar viabilizar essas proposiçóes, o PDE também se vinculou ao Programa de Aceleração do Crescimento (PAC), criado pelo governo federal, na época, a título de assegurar um conjunto de regras, compromissos de ação e diretrizes de governo que visavam um crescimento econômico de $5 \%$ ao ano no período que lhe correspondeu. Houve programação de investimentos em infraestrutura, incentivos tributários, arranjos de compromissos de política fiscal, monetária e manutenção da política social do Estado no que se refere à previdência, assistência de saúde e educação básica. O PAC pretendeu inaugurar uma nova fase na política econômica do governo de Luís Inácio da Silva, recolocando na agenda do país a temática do crescimento. Entretanto, conservou sua política social e educacional de cunho neoliberal, reorganizando os programas para controlar e fiscalizar os recursos destinados a esses setores. 
Um documento lançado pelo MEC posteriormente à data oficial do decreto já mencionado, no livro Plano de Desenvolvimento da Educação: razóes, princípios e programas, apresenta a seguinte justificativa:

O PDE, nesse sentido, pretende ser mais do que a tradução instrumental do Plano Nacional de Educação (PNE), o qual, em certa medida, apresenta um bom diagnóstico dos problemas educacionais, mas deixa em aberto a questão das açốes a serem tomadas para a melhoria da qualidade da educação. É bem verdade, como se verá em detalhe a seguir, que o PDE, também pode ser apresentado como plano executivo, como conjunto de programas que visam dar conseqüência às metas quantitativas estabelecidas naquele diploma legal, mas os enlaces conceituais propostos tornam evidente que não se trata, quanto à qualidade, de uma execução marcada pela neutralidade. Isso porque, de um lado, o PDE está ancorado em uma concepção substantiva de educação que perpassa todos os níveis e modalidades educacionais e, de outro, em fundamentos e princípios historicamente saturados, voltados para a consecução dos objetivos republicanos presentes na constituição, sobretudo no que concerne ao que designaremos por visão sistêmica da educação e à sua relação com a ordenação territorial e o desenvolvimento econômico e social. (BRASIL, 2007, p. 7)

No conjunto dos programas, observa-se a presença da relação entre financiamento, gestão e avaliação. Foi uma das principais matrizes que balizam a função do Estado no que diz respeito às políticas públicas de educação, iniciadas desde os anos de 1970, ao submeterem seus programas educacionais à lógica economicista sob o modelo da produtividade e competitividade, justificando que é possível uma maior eficácia controlando melhor os recursos. Sobre essas consideraçóes, Sobrinho (2004), no texto "Avaliação ética e política em função da educação como direito público ou como mercadoria?", comenta:

Desde a crise econômica e o aumento das demandas sociais dos anos de 1970, ou seja, com a diminuição dos recursos públicos para os setores sociais coincidindo com a crescente complexidade da sociedade, nos países industrializados, os Estados aumentaram consideravelmente as suas açôes de controle e fiscalização. Este fenômeno se tornou conhecido com o "Estado Avaliador", segundo expressão cunhada por Guy Neave, e caracteriza a forte presença do Estado no controle dos gastos e dos resultados das instituiçôes e dos órgãos públicos. O "Estado Avaliador" intervém para 
assegurar mais eficiência e manter o controle daquilo que considera ser qualidade. (SOBRINHO, 2004, p. 708)

Assim, no Brasil, o processo avaliativo nos sistemas educacionais ultrapassou a visão formativa e de emancipação pessoal e social que predominou até os anos de 1960. Fortaleceu-se o viés da avaliação na perspectiva técnica e econômica, com o objetivo de colaborar com aqueles que defendiam o funcionamento da escola com as mesmas regras do mercado. Segundo um estudo de Freitas (2007) - no livro A avaliação da educação básica no Brasil: dimensão normativa, pedagógica e educativa -, a concepçáo de avaliação com essa orientação, focalizada mais na relação entre gestão e financiamento, para garantir uma eficácia, vem se consolidando nas últimas décadas, pois em legislaçóes anteriores essa relação não era táo explícita. Ela aparece na Lei n. 9.394, de 20 de dezembro de 1996 (Lei de Diretrizes Básicas da Educação Nacional/ LDB):

Art. 9o A União incumbir-se-á de: (Regulamento)

$\mathrm{V}$-_coletar, analisar e disseminar informaçôes sobre a educação;

VI - assegurar processo nacional de avaliação do rendimento escolar no ensino fundamental, médio e superior, em colaboração com os sistemas de ensino, objetivando a definiçáo de prioridades e a melhoria da qualidade do ensino; Art. 211. A União, os Estados, o Distrito Federal e os Municípios organizarão em regime de colaboração seus sistemas de ensino.

$\$ 1^{\circ}$ A União organizará o sistema federal de ensino e o dos Territórios, financiará as instituiçóes de ensino públicas federais e exercerá, em matéria educacional, função redistributiva e supletiva, de forma a garantir equalização de oportunidades educacionais e padrão mínimo de qualidade do ensino mediante assistência técnica e financeira aos Estados, ao Distrito Federal e aos Municípios. (BRASIL, 1996/2012)

Os processos avaliativos, como se observa na leitura da LDB, além de passarem a diagnosticar e permitir o aperfeiçoamento dos programas, poderão disponibilizar, conforme o desempenho, os recursos financeiros e pedagógicos. Essa perspectiva é apresentada no livro já citado sobre o PDE, como ponto de maior relevância:

O PDE promove profunda alteração na avaliação da educação básica. Estabelece, inclusive, inéditas conexôes entre avaliação, financiamento e gestấo, que invocam conceito até agora ausente do nosso sistema educacional: a responsabilização e, como decorrência, a mobilizaçáo social. (BRASIL, 2007, p. 19) 
Em nome da responsabilização submetida ao conceito de eficácia, a avaliaçáo tem sido adotada amplamente pelo Brasil em quase todos os estados e municípios e incentivada pelos organismos multilaterais, que, muitas vezes, financiam os projetos educacionais, como o Banco Mundial. Na pesquisa Cartografia da avaliaçáo educacional do Brasil, Lopes (2007) verificou que, dos 27 estados federados, 14 possuem seus próprios sistemas de avaliação. Acerca dessa prática, Souza e Oliveira (2003, p. 874-875) analisam:

[A] centralidade adquirida pela avaliação nas políticas educacionais tem sido apresentada e justificada como propulsora de sua qualidade, substituindo a antiga idéia força da igualdade. Essa contraposição entre qualidade e igualdade torna-se mais clara quando compreendida dentro dos marcos gerais das reformas educacionais. De um lado, centralizam-se os processos avaliativos e de outro descentralizam-se os mecanismos de gestão e financiamento, tornando-os meios destinados a otimizar o produto esperado, os bons resultados no processo educativo. A avaliação torna-se um mecanismo indutor da excelência e como desdobramento naturaliza- se a desigualdade. Ela encerra duas potencialidades: peça central nos mecanismos de controle, que se deslocam dos processos para os produtos. Não importa como ocorre o processo ensino- aprendizagem, desde que ocorra. E a outra legitima valoraçôes úteis à indução de procedimentos competitivos entre escolas e sistemas para melhorar pontuaçôes nos rankings. Tal competição é garantida pela associação entre desempenho e financiamento: critérios para alocação de recursos, remuneração diferenciada e náo isonômica.

Assim, os programas de avaliação realizados pelo governo federal a partir dos anos de 1990, como o Sistema Nacional de Avaliação Básica (Saeb), Exame Nacional do Ensino Médio (Enem) e Exame Nacional de Cursos (ENC, chamado Prováo), consolidaram essa perspectiva. Esses programas foram alvos de crítica no Programa de Governo Lula 2002, onde se afirmava que:

A capacidade formuladora e de controle está fortemente concentrada no governo federal, via mecanismos centralizadores como os Parâmetros Curriculares Nacionais, a exigência de adesão aos programas de reformas educacionais como condição de acesso a recursos, procedimentos de avaliação centralizados e classificatórios. O controle centralizado do governo federal em avaliaçóes implementadas, como o Exame Nacional do Ensino Médio (ENEM) e o Exame Nacional de Cursos (PROVÃO) têm focalizado mais 
o produto final do que o processo educativo. Essa forma de avaliação náo deve servir para destacar meramente a classificaçáo dos Estados quanto à educação básica e à competição entre universidades. (COLIGAÇÃO..., 2002, p. 3)

Entretanto, ao assumir o governo em 2003, Luís Inácio da Silva deu continuidade a essas açóes avaliativas nos vários níveis de ensino. O então ministro Fernando Haddad justificou o ajuste no Saeb, criando a Avaliação do Rendimento Escolar (Anresc), mais conhecida pela Prova Brasil, em 2005:

O Sistema de Avaliação da Educação Básica (Saeb) é um exame aplicado a cada dois anos a uma amostra de alunos de cada Estado, acompanhado de um questionário. Trata-se de uma ferramenta útil, que permite estabelecer correlaçôes estatísticas entre o desempenho dos alunos e um conjunto de variáveis, como perfil do corpo docente, infra-estrutura da escola etc. Contudo, como a amostra náo é representativa dos alunos de cada sistema municipal ou de cada escola, ela não permite ao prefeito, por exemplo, saber se o sistema educacional por ele gerenciado se distingue dos demais sistemas municipais. Muito menos dá condições à diretora da escola de saber se seus esforços para melhorar as condiçóes de ensino no seu estabelecimento produzem ou não resultados comparativamente aos demais. Com o Saeb ampliado - a Prova Brasil -, cada prefeito, secretário de Educação e diretora de escola receberá um relatório sobre a posição relativa de cada escola, possibilitando corrigir as deficiências e disseminar as boas práticas que serão identificadas. (HADDAD, 2008, p. 1)

Ainda nesse sentido, caminharam os programas de avaliação referendados no Programa Setorial de Educação 2007/2010 e nas novas açóes avaliativas apresentadas no PDE/2007. Atualizaram-se programas, como o Saeb e a Prova Brasil, iniciativas anteriores do MEC para avaliar o desempenho dos alunos e das escolas. Criou-se o Índice de Desenvolvimento da Educação Básica (Ideb), que tem como parâmetros o rendimento dos alunos na Prova Brasil, no Saeb, além dos indicadores de fluxo (taxa de promoção, repetência e evasão escolar) obtidos pelo Educasenso, que atrela o financiamento e a orientação técnica aos resultados do Ideb. Em uma escala de 0 a 10, estabeleceram-se metas progressivas para se atingir a média 6,0 - nota dos países que agregam a Organização para a Cooperação e Desenvolvimento Econômico (OCDE) - até 2022, data escolhida simbolicamente por representar os duzentos anos da Independência do Brasil. Cada estado, 
município e escola têm calculado seu Ideb, e o MEC disporá de recursos financeiros e pedagógicos para reformular e propor ações que ajudarão a escola a atingir sua meta de Ideb. A finalidade do programa é assim justificada:

Com o IDEB, ampliam-se as possibilidades de mobilização da sociedade em favor da educação, uma vez que o índice é comparável nacionalmente e expressa em valores os resultados mais importantes da educação: aprendizagem e fluxo. A combinação de ambos tem também o mérito de equilibrar as duas dimensóes: se um sistema de ensino retiver seus alunos para obter resultados de melhor qualidade no SAEB ou Prova Brasil, o fator fluxo será alterado, indicando a necessidade de melhoria do sistema. Se, ao contrário, o sistema apressar a aprovação do aluno sem qualidade, o resultado das avaliaçóes indicará igualmente a necessidade de melhoria do sistema. (BRASIL, 2008a, p. 1)

Criou-se também a Provinha Brasil, que pretende garantir que toda criança de oito anos saberá ler e escrever, conforme meta prevista pelo Plano de Metas Compromisso de Todos pela Educação. De acordo com o programa, a Provinha Brasil é uma avaliação diagnóstica que permite auxiliar professores, coordenadores e gestores a identificar o desempenho de alunos em processo de alfabetização, no segundo ano de escolaridade do ensino fundamental. Sua aplicação aconteceu em 2008, conforme adesão voluntária do município. A intenção do programa é a de que as informaçóes geradas ajudem a compreender quais são as capacidades já dominadas pelos alunos e quais deverão ser apreendidas ao longo do ano escolar. Segundo o documento, "essa avaliação diferencia-se das demais que vêm sendo realizadas pelo Inep porque poderá fornecer respostas diretamente aos professores e gestores da escola, reforçando assim uma de suas características, que é a de um instrumento pedagógico sem finalidades classificatórias" (BRASIL, 2008b, p. 1).

Essas ações pretendem atacar o problema qualitativo da educação, mas seu foco principal continua sendo a eficiência, consoante à ideia de produzir mais com menos gastos, estratégia do Estado Avaliador. As implicaçóes dessa tendência, explorando apenas os rendimentos dos alunos e das escolas, por meio desses indicadores, acabam colaborando para dar visibilidade à classificação e exercer uma pressão sobre os alunos, professores e instituiçóes. Não se percebe uma referência ao contexto mais amplo do sistema educacional, com informaçóes de fatores que interfiram dinamicamente nesses resultados. 
Ao analisar o Saeb, por exemplo, Sousa (2002, p. 32) observou que a questão central desse tipo de sistema de avaliação "não é de buscar subsídios para intervençóes mais precisas e consistentes do poder público, mas sim instalar mecanismos que estimulem a competição das escolas, responsabilizando-as, em última instância, pelo sucesso ou fracasso escolar”. Lopes (2008), no artigo, veiculado pela internet, analisa que a metodologia usada para aplicação e análise das avaliaçóes é de domínio apenas do MEC e das agências contratadas para sua aplicação, o que dificulta a interpretação dos resultados pelos gestores, especialistas da área e pela comunidade escolar.

Até o momento, são poucas as evidências de que os resultados dessas avaliações foram apropriados para gerarem impactos positivos sobre a qualidade de ensino, conforme alguns exemplos citados por Sousa (2008). Essas iniciativas têm gerado comparação entre as unidades escolares que são classificadas, contribuindo ainda mais para fortalecer o papel regulador/avaliador do Estado. Na divulgação do Ideb, em junho de 2009, por exemplo, quando o MEC apresentou os resultados, secretários de educação questionaram a posição exibida do seu estado, observando que havia dados incorretos na verificação conduzida pelo ministério. Além disso, com raras exceções, os resultados viraram manchetes na imprensa, banalizando algo que merecia maior esclarecimento e mais debate.

Tomar o sistema de avaliação de maneira censitária é preocupante, pois estimula a competição e pode desencadear um processo de usos de resultados para premiação ou punição das escolas. A esse respeito, conforme Sousa (2008), alguns estados, como São Paulo e Ceará, instituíram prêmios às escolas que se saíram bem nos exames.

Em 2011, por exemplo, a ideia de difundir a nota do Ideb nas portas das escolas, lançada na edição 8 da revista Veja de 2011 pelo empresário e economista Gustavo Ioschipe, ganhou adeptos nas assembleias legislativas. Apresentaram-se vários projetos de lei nesse sentido, como, por exemplo, o de autoria do deputado federal Ronaldo Caiado (DEM/Goiás). A discussão de tal intenção também ocorreu no Senado pela iniciativa da senadora Lúcia Vânia (PSDB/Goiás).

Mesmo com as várias críticas que as ações avaliativas recebem, no atual momento, no governo de Dilma Rousseff, em que a base administrativa do MEC continua sendo a mesma, fica difícil vislumbrar outro paradigma para fomentar ações avaliativas para além das questôes da relação gestão e financiamento nos moldes de uma lógica mercadológica. 
A relação entre avaliação e melhoria da qualidade do ensino não se constitui de modo simples e direto. Ela só poderá ganhar sentido quando explorar outros fatores, além dos resultados nucleares sobre rendimentos dos alunos e das escolas. A avaliação é um processo complexo e tem uma dimensão ética e política que envolve a sociedade. Problematizá-la faz-se necessário quando se cogita melhorar a qualidade do ensino oferecido nas instituiçóes educativas, tendo em vista um processo bem mais amplo, que é a educação.

\section{Referências}

BRASIL. Lei n. 9.394, de 20 de dezembro de 1996 (Lei de Diretrizes Básicas da Educação Nacional/LDB). Disponível em: <www. portal.casacivil. gov.br/arquivos/pdf>. Acesso em: 10 jan. 2012.

. Decreto n. 6094. Disponível em: <www. portal.mec.gov.br/arquivos/pdf>. Acesso em: 27 jan. 2012.

MEC. Plano de desenvolvimento da educação: razóes, princípios e programas. 2007.

. MEC. IDEB. Disponível em: <wwwportal.mec.gov.br/arquivos//>. Acesso em: 10 jan. 2012. 2008a.

. Provinha Brasil. Disponível em: <wwwportal.mec.gov.br/arquivos>. Acesso em: 10 jun. 2012. 2008b.

COLIGAÇÃO Lula Presidente. 2002. Programa de Governo Lula 2002. Uma escola do tamanho do Brasil. Brasil, 2002.

. 2007. Programa Setorial de Educação 2007/2010. Brasil, 2007.

FREITAS, D. N. T. de. A avaliação da educação básica no Brasil: dimensão normativa, pedagógica e educativa. Campinas: Autores Associados, 2007.

HADDAD, F. Educação e avaliação. Brasília. Disponível em: <www.imprensa@mec.gov>. Acesso em: 13 jul.2012.2008.

LOPES, V. V. Cartografia da avaliação educacional no Brasil. 2007. Tese Faculdade de Educação, Universidade de São Paulo (USP), São Paulo. 2007.

. Hora de decifrar os números. Disponível em: <www.cartanaescola. com.br>. Acesso em: 17 jun. 2012. 2008. 
NEVES, L. M. W. (Org.) A nova pedagogia da hegemonia: estratégias do capital para educar o consenso. São Paulo: Xamã, 2005.

SAVIANI, D. O Plano de Desenvolvimento da Educação: Análise do Projeto do MEC. Educação \& Sociedade. Campinas, v. 28, n. 100 (Especial), p. 1231-1255, out. 2007.

SOBRINHO, J. D. Avaliação ética e política em função da educação como direito público ou como mercadoria? Educação \& Sociedade. Campinas v. 25, n. 88 (Especial), p.703-725, out. 2004.

SOUSA, M. Z. L. Possíveis impactos da avaliação externa no currículo escolar. In: ROSA, D. E. G. e SOUZA, V. C. (Orgs.). Políticas Organizativas e curriculares, educação inclusiva e formação de professores. Goiânia: Editora Alternativa, 2002.

Avaliação da educação básica e gestão de políticas públicas: uma relação em construção. In: Encontro Nacional de Didática e Prática de Ensino (Endipe). Anais. Porto Alegre, 2008. p. 689-701.

; OLIVEIRA, R. P. Políticas de avaliação da educação e quase mercado no Brasil. Educação \& Sociedade. Campinas, v. 24, n. 84, p. 873-896, set. 2003.

Recebido em: 20 jun. 2011.

Aceito em: 15 set. 2011. 